\title{
Emerging new therapeutic applications of capecitabine as a first-line chemotherapeutic agent in the management of advanced carcinomas other than colorectal carcinoma
}

This article was published in the following Dove Press journal:

Cancer Management and Research

7 May 2012

Number of times this article has been viewed

Shailendra Kapoor

Richmond,VA, USA
Correspondence: Shailendra Kapoor 2300 E Cary Street, Richmond, VA 23223, USA

Email shailendrakapoor@yahoo.com
I read with great interest the recent article by Hameed et al in a recent issue of your journal. ${ }^{1}$ The article is very interesting. Interestingly, the past few years have seen the emergence of capecitabine as a highly potent first-line chemotherapeutic agent against advanced systemic carcinomas other than colorectal carcinoma.

For instance, capecitabine has recently been used successfully as a first-line monotherapeutic agent for HER-2-negative metastatic breast cancer. ${ }^{2}$ Cotherapy with agents such as sorafenib and paclitaxel for HER-2-negative metastatic breast cancer has also been recently used first-line, and significantly improves progressionfree survival, in addition to being very safe. ${ }^{3,4}$ Similarly, in patients with advanced gastric carcinoma, capecitabine has been used successfully as first-line therapy in combination with agents such as cisplatin. ${ }^{5}$ The XELOX regimen comprising capecitabine in conjunction with oxaliplatin is another recent highly effective alternative for gastric carcinoma. ${ }^{6}$ The modified XELIRI regimen compromising capecitabine and irinotecan is a further option for advanced and unresectable gastric carcinoma. ${ }^{7}$

Capecitabine also improves the short-term response in patients with esophageal carcinoma when used as an adjunct to radiotherapy. ${ }^{8}$ Further, a response rate of $26.7 \%$ has recently been reported in patients with advanced biliary carcinoma treated with a combination of capecitabine and fixed dose rate gemcitabine therapy. ${ }^{9}$ Similarly, capecitabine has recently been shown to be highly effective in the management of patients with recalcitrant castrate-resistant prostate cancer when used in combination with prednisone, thalidomide, and cyclophosphamide. ${ }^{10}$ Capecitabine in combination with cisplatin has also been used as first-line therapy for nasopharyngeal carcinoma, with a response rate as high as $53.8 \% .{ }^{11}$

The above examples clearly illustrate the efficacy of capecitabine as a potent agent against multiple carcinomas, ranging from breast carcinoma to nasopharyngeal carcinoma. Further studies are needed to identify further potential applications of capecitabine in other advanced carcinomas.

\section{Disclosure}

The author reports no conflicts of interest in this work. 


\section{References}

1. Hameed H, Cassidy J. Use of capecitabine in management of early colon cancer. Cancer Manag Res. 2011;3:295-299.

2. O'Shaughnessy JA, Kaufmann M, Siedentopf F, et al. Capecitabine monotherapy: review of studies in first-line HER-2-negative metastatic breast cancer. Oncologist. March 14, 2012. [Epub ahead of print.]

3. Baselga J, Segalla JG, Roche H, et al. Sorafenib in combination with capecitabine: an oral regimen for patients with HER2-negative locally advanced or metastatic breast cancer. J Clin Oncol. March 12, 2012. [Epub ahead of print.]

4. Chitapanarux I, Kamnerdsupaphon P, Tharavichitkul E, et al. Capecitabine and weekly paclitaxel as first-line therapy in Thai patients with metastatic breast cancer. Asia Pac J Clin Oncol. 2012;8:76-82.

5. Wu J, Ryan T, Levinson B, Newman E, Hochster HS, Muggia F. Cisplatin with capecitabine: tolerance and activity in a Phase I/II study preferentially enrolling patients with gastric cancer. Anticancer Res. 2012;32:939-945.

6. Xiang XJ, Zhang L, Qiu F, et al. A Phase II study of capecitabine plus oxaliplatin as first-line chemotherapy in elderly patients with advanced gastric cancer. Chemotherapy. 2012;58:1-7.
7. Luo HY, Wang ZQ, Wang FH, et al. Phase 2 study of capecitabine and irinotecan combination chemotherapy (modified XELIRI regimen) in patients with advanced gastric cancer. Am J Clin Oncol. 2011;34: 555-560.

8. Sheng W, Feng XZ, Han JQ. Efficacy of late accelerated hyperfractionated conformal radiotherapy combined with capecitabine for esophageal carcinoma. Zhonghua Zhong Liu Za Zhi. 2011;33:702-706.

9. Santini D, Virzi V, Vasile E, et al. A Phase II trial of fixed-dose rate gemcitabine plus capecitabine in metastatic/advanced biliary tract cancer patients. Oncology. 2012;82:75-82.

10. Meng LJ, Wang J, Fan WF, Pu XL, Liu FY, Yang M. Evaluation of oral chemotherapy with capecitabine and cyclophosphamide plus thalidomide and prednisone in prostate cancer patients. J Cancer Res Clin Oncol. 2012;138:333-339.

11. Chua DT, Yiu HH, Seetalarom K, et al. Phase II trial of capecitabine plus cisplatin as first-line therapy in patients with metastatic nasopharyngeal cancer. Head Neck. November 11, 2011. [Epub ahead of print.]
Cancer Management and Research

\section{Publish your work in this journal}

Cancer Management and Research is an international, peer-reviewed open access journal focusing on cancer research and the optimal use of preventative and integrated treatment interventions to achieve improved outcomes, enhanced survival and quality of life for the cancer patient. The journal welcomes original research, clinical \& epidemiological

\section{Dovepress}

studies, reviews \& evaluations, guidelines, expert opinion \& commentary, case reports \& extended reports. The manuscript management system is completely online and includes a very quick and fair peerreview system, which is all easy to use. Visit http://www.dovepress.com/ testimonials.php to read real quotes from published authors. 